\title{
5.2 Existential-axiological dimension of decriminalization of consciousness and society
}

In modern conditions, the question of determining the moral component of modern man in a rapidly changing world arises with new urgency. Today, when the world is facing impending globalization, the crisis of the European spirit, the destruction of values and theoretical ideas that seemed until recently strong and the only true, the question of the ontological foundations of human life is especially relevant philosophical research criminalization and decriminalization of consciousness and society.

The problem of criminalization and decriminalization of consciousness and society can not be considered in only one dimension, because these phenomena are closely related to both individual consciousness and the consciousness of a social unit. The latter is closely related to the phenomenon of identity, inherent in any human group. As L. Kolakovsky notes, the problem of collective identity is similar to the problem of personal identity [139, p.103].

That is why it is impossible to understand the essence of the first without analyzing the essence of the second, because certain aspects of personal identity have analogues in collective ways of life. Among such parties the author singles out: 1) substance or soul, or the intangible side of the personality; despite various discussions about the existence or non-existence of this phenomenon, which is not easy for empirical knowledge, in everyday experience every mentally healthy person uses the pronoun "I", with which he identifies his personality; without denying the duration of "I" there are serious problems with the phenomenon of personal responsibility and the very essence of public life; 2) memory is the next component of personal identity, because without the existence of the work of memory to talk about the continuity of "I" does not make sense; 3) focus on the future - is a kind of conscious project, which passes in the time coordinate system, and is existentially emotionally colored; 4) the body, which is an integral part of the identity of the human person, despite the fact that it itself is undergoing constant changes in the time continuum of existence; 5) a person's confidence that he has a beginning, which the latter can localize in time, despite the 
fact that purely physiologically can not remember its beginning in existence [139, p.105].

Now, considering all these characteristics, but in relation to collective identity, L. Kolakovsky reveals the structure and internal dynamic forces of collective identity. Thus, what is analogous to the metaphysical concept of substance in personal identity, in the collective dimension will be close to the concept of "national spirit", which is expressed in various forms of cultural life and collective action, and becomes especially pronounced in times of crisis. In fact, this spirit is a kind of basis for cultural phenomena, it is one that does not identify with them. It is also difficult to overestimate the place of historical for national identity. Such memory is often mixed with ideology, so it may not coincide with the historical chronology of events in its history. Nevertheless, for national identity, it is vital to realize that that the nation is a kind of continuation of what once existed in the past. The value of foresight, as well as for personal identity and national identity, is difficult to overestimate. Such foresight is closely related to the goal, which is often the main object of purposeful existence at both the individual and national-ethnic levels. The next aspect of collective identity, analogous to which is the body for personal identity, is territory. In the event that the people lost their territory, this role was often played by a common religion. An example of such a state is the history of the Jewish people. Finally, localization in time is almost always present in the cultural and ideological memory of the people, expressed in the forms of legends, songs, which refer to the act of foundation or the first ancestors that existed once in the past. The value of foresight, as well as for personal identity and national identity, is difficult to overestimate. Such foresight is closely related to the goal, which is often the main object of purposeful existence at both the individual and national-ethnic levels. The next aspect of collective identity, analogous to the body for personal identity, is territory. In the event that the people lost their territory, this role was often played by a common religion. An example of such a state is the history of the Jewish people. Finally, localization in time is almost always present in the cultural and ideological memory of the people, expressed in the forms of legends, songs, which refer to the act of foundation or the first ancestors that existed once in the past. The 
value of foresight, as well as for personal identity and national identity, is difficult to overestimate. Such foresight is closely related to the goal, which is often the main object of purposeful existence at both the individual and national-ethnic levels. The next aspect of collective identity, analogous to the body for personal identity, is territory. In the event that the people lost their territory, this role was often played by a common religion. An example of such a state is the history of the Jewish people. Finally, localization in time is almost always present in the cultural and ideological memory of the people, expressed in the forms of legends, songs, which refer to the act of foundation or the first ancestors both for personal identity and for national identity, it is difficult to overestimate. Such foresight is closely related to the goal, which is often the main object of purposeful existence at both the individual and national-ethnic levels. The next aspect of collective identity, analogous to the body for personal identity, is territory. In the event that the people lost their territory, this role was often played by a common religion. An example of such a state is the history of the Jewish people. Finally, localization in time is almost always present in the cultural and ideological memory of the people, expressed in the forms of legends, songs, which refer to the act of foundation or the first ancestors both for personal identity and for national identity, it is difficult to overestimate. Such foresight is closely related to the goal, which is often the main object of purposeful existence at both the individual and national-ethnic levels. The next aspect of collective identity, analogous to which is the body for personal identity, is territory. In the event that the people lost their territory, this role was often played by a common religion. An example of such a state is the history of the Jewish people. Finally, localization in time is almost always present in the cultural and ideological memory of the people, expressed in the forms of legends, songs, which refer to the act of foundation or the first ancestors which is often the main object of purposeful existence both at the individual level and at the nationalethnic level. The next aspect of collective identity, analogous to the body for personal identity, is territory. In the event that the people lost their territory, this role was often played by a common religion. An example of such a state is the history of the Jewish people. Finally, localization in time is almost always present in the cultural and 
ideological memory of the people, expressed in the forms of legends, songs, which refer to the act of foundation or the first ancestors which is often the main object of purposeful existence both at the individual level and at the national-ethnic level. The next aspect of collective identity, analogous to which is the body for personal identity, is territory. In the event that the people lost their territory, this role was often played by a common religion. An example of such a state is the history of the Jewish people. Finally, localization in time is almost always present in the cultural and ideological memory of the people, expressed in the forms of legends, songs, which refer to the act of foundation or the first ancestors then this role was often performed by a common religion. An example of such a state is the history of the Jewish people. Finally, localization in time is almost always present in the cultural and ideological memory of the people, expressed in the forms of legends, songs, which refer to the act of foundation or the first ancestors then this role was often performed by a common religion. An example of such a state is the history of the Jewish people. Finally, localization in time is almost always present in the cultural and ideological memory of the people, expressed in the forms of legends, songs, which refer to the act of foundation or the first ancestors [139, p. 101-105].

Human consciousness, connected with the public consciousness by numerous connections, will always be marked by a great social influence in the legal dimension. Such a close connection is based on the internal structure of the human personality, the social dimension of which was formed over many centuries of experience of coexistence in conditions of various kinds of hostility to the external environment. However, it should also be noted that this social dimension is not only the result of a long history of human evolution, but also an important manifestation of the transcendental-axiological dimension of the human personality, and to such an extent that in a state of social self-isolation all their consciousness, in this state a person often begins to lose the meaning of his life. As noted by EN Trubetskoy: "in selfish assertion, in separation from other people my life is meaningless and meaningless, because the objective good is in the union of all; ... The meaning of life is revealed in love and only 
in it; the path of selfishness is revealed as untruth in any careful and profound philosophical analysis, and the path of solidarity is revealed as truth "[142, p. 219].

Such a close connection of the individual with society is also found in the legal dimension. After all, the personal system of assessment of legal reality is largely a reflection of the general mentality of a particular ethnic group. At the same time, it should be noted: each individual perceives the attitudes of society not just mechanistically, but also through the personal-individual factor. Thus, in the legal dimension it is important not only one or another legal imperative that comes from society, but also the position of the individual himself: whether to perceive it and make it a valuable part of their own perception of reality, or, conversely, distance themselves from the latter by choosing a personal line behavior that pays little attention to the axiological meaning of the social and legal imperative. In this case, the individual will consider the criminal prohibition only on the grounds of preventing punitive sanctions, provided for violation of this prohibition. Of course, this approach is not entirely effective in reducing the criminalization of society. The most effective will be a genuine, deep perception of the requirements of society in the legal field and the integration of social and legal values into its own hierarchy of axiological dimension.

An important prerequisite for this is the moral and axiological healthy state of relations in society itself. Otherwise, the average individual, considering the behavioral and legal imperatives recorded in various official documents, propagated through various media, seeing that the latter are really just a means of control by one part of society to another, will not be able to accept these imperatives. If he sees in such imperatives a real benefit for the common good of all, he will be able, based on his own conviction, and not only on the fear of punitive sanctions, to accept these imperatives as if they were his own.

The legal dimension is deeply rooted in the structure of the human personality. And many illegal actions a morally healthy person will not perform not only out of fear of punishment, but also out of self-belief. At the same time, in the presence of injustice in the socio-legal dimension, a person cannot find that axiologically convincing support for certain prescriptions, and therefore in his mind considers himself free from 
prescriptions that in an unjust situation do not seem to be fulfilled. One example of this state of affairs is the situation that is often encountered in the functioning of totalitarian regimes.

The latter, grossly violating human rights, issue inhumane laws, which, due to their opposition to the natural rights of the human person, are effectively perceived by citizens of such regimes as illegitimate laws and as those whose implementation cannot be based on deep inner conviction. Thus, due to the gross violation of natural human rights and the existence of injustice in relation to the "state-man" in the minds of many ordinary citizens of the USSR was not considered theft of agricultural products for which they worked, where wages are unfairly underestimated by the employer. It has been repeatedly said that individuals who did so explained this behavior by saying that they "did not steal, but took their own." That is why "any criminal law decision of a criminalizing or decriminalizing nature must be made taking into account the predictability of its interaction with the system of individual rating scales ..., taking into account the possible attitude of the individual to criminal law. At the same time ... the development and assimilation of patterns of behavior depends not only on the type of social formation, but also on specific values and socio-psychological stereotypes that divide different social groups, as well as on individual characteristics "development and assimilation of patterns of behavior depend not only on the type of social formation, but also on specific values and socio-psychological stereotypes that divide different social groups, as well as on individual characteristics of the individual " development and assimilation of patterns of behavior depend not only on the type of social formation, but also on specific values and socio-psychological stereotypes that divide different social groups, as well as on individual characteristics of the individual "[138, p. 223].

Despite the not always successful implementation of law in the human dimension of existence, it should be noted: the absolute idea of law as such is part of the world ethical order, has an objective existence, and which does not depend on whether a person is aware of it or not. Just as objectively and independently of human consciousness, there are various laws of nature. At the same time, the natural law, 
which is self-evident for each person, is self-evident only in its general provisions: for each morally mature person the requirements of respect for other people's rights, observance of honesty in relations with people, etc. are clear. However, for the existence of human society in the historical-temporal continuum, it is extremely important to have more specific definitions of the action of natural law in certain cases of human existence. It is the positive right that is the essence, which performs this role of applying natural law to the real existential-temporal situation of human existence. As noted by IV Mikhailovsky, "positive law is the implementation of" natural law "in a particular social environment. This implementation is due to the data of place and time and therefore is nothing immutable; the conditions of one environment differ from the conditions of another, and therefore the law of one state may differ significantly from the law of another, the law of the state in one era may be opposite to the law of the same state in another ". the conditions of one environment differ from the conditions of another, and therefore the law of one state may differ significantly from the law of another, the law of the state in one era may be opposite to the law of the same state in another " the conditions of one environment differ from the conditions of another, and therefore the law of one state may differ significantly from the law of another, the law of the state in one era may be opposite to the law of the same state in another "[141, p. 307].

Of course, changes in positive law can vary considerably depending on the era, but it should be noted that these changes cannot be contrary to natural law. Otherwise, we can talk about a certain illegitimacy of the functioning of such a right, which would be contrary to the natural, because such a positive right would lose this metaphysicalaxiological basis, which makes it legitimate.

In fact, in this perspective, the importance of the "individual-state" relationship for understanding the causes and mechanisms of criminalization of individual and social consciousness becomes clear. The more unjust the policy of the state, the greater will be the distrust of the population in the legal dimension of its activities, and the greater will be the drift towards the criminalization of society and, consequently, public consciousness. The more a state violates the natural rights of the human person, the 
greater the danger of the prosperity of various criminal factors in the existence of such a state, which will result in the deterioration of the living conditions of the majority of the country's population. At the same time, it should also be noted that different forms of crime in socio-historical periods will also be different, and, accordingly, there will be other aspects of human existence that will deteriorate.

In this perspective, the data of an all-Russian survey conducted in 1999 by the Center for Social Forecasting are very valuable. The sample was based on the principle of cohort analysis, where the sample was built on the basis of five groups, divided by age, respectively: 18-25, 26-36, 37-47, 47-57, 57-67 years. It included 3,000 people, 600 in each group.

Residents of large metropolises, regional and district cities, as well as those who lived in working-class settlements and villages took part in the surveys. As for the socio-professional dimension of respondents, in this case, the respondents included representatives of almost all segments of the population, including workers and engineers of enterprises, mines and buildings, humanitarian and creative intelligentsia, workers in communications, transport and trade, entrepreneurs small and medium business, representatives of law enforcement agencies, villagers, retirees, as well as university students, students of vocational schools and 10-11 grades of secondary schools. Of particular interest was the survey on the characteristics of which characteristics are inherent in certain historical periods of Russia and the USSR. After all, we know from history: in the territory of present-day Russia for a long time there was a constant process of change of corporate power structures, which was often accompanied by the eradication of historical memory. Historical consciousness, on the one hand, is always based on a certain acceptability of traditions, as well as significantly influenced by ideological factors, and on the other - such consciousness is the result of a synthesis of personal social experience and a set of social norms that a particular individual perceived as a result of socialization. orientations. Due to the phenomenon of constant change in the historical memory of the people, caused by various ideological motives, several generations of Russians have had to rethink their views on the historical events in which they participated several times in their lives. 
which was often accompanied by the eradication of historical memory. Historical consciousness, on the one hand, is always based on a certain acceptability of traditions, as well as significantly influenced by ideological factors, and on the other - such consciousness is the result of a synthesis of personal social experience and a set of social norms that a particular individual perceived as a result of socialization. orientations. Due to the phenomenon of constant change in the historical memory of the people, caused by various ideological motives, several generations of Russians have had to rethink their views on the historical events in which they participated several times in their lives. which was often accompanied by the eradication of historical memory. Historical consciousness, on the one hand, is always based on a certain acceptability of traditions, as well as is significantly influenced by ideological factors, and on the other - such consciousness is the result of a synthesis of personal social experience and set of norms of society. orientations. Due to the phenomenon of constant change in the historical memory of the people, caused by various ideological motives, several generations of Russians have had to rethink their views on the historical events in which they participated several times in their lives. and on the other hand, such consciousness is the result of a synthesis of personal social experience and a set of norms of society, which a particular individual perceived as a result of the process of socialization into his system of value orientations. Due to the phenomenon of constant change in the historical memory of the people, caused by various ideological motives, several generations of Russians have had to rethink their views on the historical events in which they participated several times in their lives. and on the other hand, such consciousness is the result of a synthesis of personal social experience and a set of norms of society, which a particular individual perceived as a result of the process of socialization into his system of value orientations. Due to the phenomenon of constant change in the historical memory of the people, caused by various ideological motives, several generations of Russians have had to rethink their views on the historical events in which they participated several times in their lives.

During the survey, the entire study period was divided into five periods: Russia before 1917, the USSR during the reign of Stalin, the USSR under Khrushchev, the 
USSR under Brezhnev, and Russia under Yeltsin. It is necessary to realize that the survey data are only representatives of the historical consciousness of those people who participated in the survey. The latter, in turn, is significantly influenced by the ideological atmosphere in which the respondents were brought up and raised. That is why we must be aware that often their assessment of particularly distant pages of history does not always correspond to historical reality in the chronologically accurate sense of the word. After all, the very concept of history is quite ambiguous, as R. Kozelek notes, conveying the ideas of Hladenius that "there is a history of modernity that encompasses all living things; then - the future history, which is always waiting for us ahead and which we anticipate in our plans, hopes and fears, and finally the ancient history, which always begins with the death of the last eyewitness ... the buildup of ancient history occurs as generations disappear "[140, p. 317].

In the perspective of our study of the phenomenon of criminalization, it is interesting to pay attention to the following characteristics of each of the surveyed periods: corruption and bribery, social injustice, crime and banditry, bureaucracy, uncertainty about their future, difficult economic situation, discipline and order. Thus, the period that is the furthest from the present - Russia before 1917, is characterized, according to respondents, by the following phenomena: the level of corruption - 4\%, social injustice $-15.7 \%$, crime and banditry $-9.7 \%$ and low level of social protection - $6 \%$. The period of existence of the USSR under the leadership of J. Stalin was marked by a high level of fear in society $-68.7 \%$, which is the highest among all periods, the presence of ideals $-59.6 \%$ and the existence of discipline and order $-84.3 \%$, love for the Motherland $-71.8 \%$. This period is also characterized by low levels of corruption and bribery $-16.2 \%$, social justice $-12.6 \%$, civil and political freedoms $-2.9 \%$, bureaucracy $-5.9 \%$, crime and banditry $-10.3 \%$, social protection $-13.0 \%$. During the Khrushchev era, the USSR had the lowest rates of fear - 3.5\%, interethnic conflicts $5.6 \%$, crime and banditry $-4.8 \%$, uncertainty in the future $-2.8 \%$. For the USSR under L. Brezhnev, the lowest indicators of difficult economic situation were $-6.3 \%$, the highest indicators of social protection $-75.9 \%$, cheerfulness $-71.5 \%$, trust between people $-68.3 \%$, respect for the Orthodox Church $-70.7 \%$. Also in this period there was 
a low level of corruption and bribery $-15.4 \%$ and crime $-7.1 \%$. For the rule of Mikhail Gorbachev compared to the reign of Leonid Brezhnev were characterized by:

As for the existence of Russia under Boris Yeltsin, according to these polls, it has such indicators that are accompanied by a difficult economic situation - $89.3 \%$, fear - 50.6\%, ethnic conflicts - 84.8\%, crime and banditry - $95.6 \%$, bureaucracy $65.2 \%$, crisis - $92,7 \%$, uncertainty in their future $-93 \%$ social injustice $-92.4 \%$ and corruption and bribery $-81.8 \%$. In this critical state, discipline and order are only $2.0 \%$. Among the positive aspects of this period can be mentioned only the belief of a large part of the population that it is possible to become rich $-75.6 \%$ and increase respect for the Orthodox Church - 58.3\%.

Analyzing the statistics, we see a clear correlation between the existence of order, favorable economic situation, the existence of ideals in society, respect for natural human rights and, consequently, low levels of corruption, bribery, crime and banditry. According to F. Sherega, each of the studied periods corresponds to a certain model of law: for example, "for the stage before 1917 it is an authoritarian pseudolegal class of government; for the Stalinist period - corporate pseudo-legal dictatorship; for the Khrushchev period - the eclecticism of pseudo-legal and authoritarian rule; for the Brezhnev period - pseudo-legal bureaucratic management, which relies on the principality; for the Gorbachev period - bureaucratic arbitrariness, which uses anarchy and ignores the law; for the Yeltsin period - oligarchic lawlessness, which, however, proclaims the priority of the rule of law "[143, p. 21].

It is significant that each of the studied forms of government is presented as pseudo-legal, as it reflects the gap that stands between the real rule of law and the sad reality witnessed by the respondents.

Thus, the truth is the position that the existence of law and order and the economy as a sphere of material social relations is the foundation of all social life. They are in charge of all other spheres of human activity - politics, culture, morality, spiritual sphere. The level of social, spiritual, cultural state of society is determined in some way by the level of economic development and law and order. However, there is an active role of morality in social development, its reverse effect onconsciousness and society. 